\title{
Prescription Grazing for Rangeland Weed Management
}

\author{
A new look at an old tool.
}

\author{
By Rachel A. Frost and Karen L. Launchbaugh
}

Invasion by exotic species is one of the most significant ecological threats of our modern era, rivaling even highly touted and researched concerns such as ozone depletion, global warming, and loss of biodiversity. An invasive plant on rangelands is defined as a plant spreading naturally (without direct human assistance) to significantly alter composition, structure or ecosystem processes. Weed invasion into rangeland communities often results in reduced biodiversity, increased soil erosion, degradation of wildlife habitat, and reduced carrying capacity for livestock.

There are many challenges when controlling invasive plants on rangelands, including vast roadless areas that limit access for weed control and lands of low economic value that make chemical and mechanical control impractical. These challenges favor biological control methods. Insects and microbes for biocontrol can be quite effective but are difficult, expensive, and time consuming to develop. However, there is a readily available and under-exploited tool that is fast proving very effective for weed control - livestock grazing.

Along with fire, grazing of domestic livestock may be the earliest vegetation management tool employed by humans. We suggest that the challenges of rangeland weed management may be addressed with the careful sharpening of this old tool. Past success with sheep and goats to control several rangeland weeds, such as leafy spurge, has fueled interest in grazing for weed control $(1,2)$.

Prescription grazing is the application of livestock grazing at a specified season, duration and intensity to accomplish specific vegetation management goals. Controlled grazing of this type is being employed throughout North America on public and private land and is proving to be a promising tool in the battle against weeds. Furthermore, livestock grazing has one distinct advantage over other control methods; in the process of controlling an undesirable plant, grazing animals convert it into a saleable product.

\section{How Livestock Can Control Weeds}

Awareness of invasive alien weeds has raised concern over the potential role livestock play in spreading these weeds and prompted a desire to remove livestock from public rangeland in some places. However, other areas are welcoming livestock in an effort to battle weeds and restore ecological health. Given the correlation between livestock grazing and alien plant invasion, why are managers now looking to livestock to control invasive plants? Just as venom can be converted into anti-venom to treat the very symptoms it caused, with proper management, grazing animals can provide more effective and sustainable weed control than herbicides alone, and can also improve pasture quality with less effect on non-target species.

While the indiscriminant grazing of livestock can result in weed-dominated plant communities, with careful management selective grazing can be used to alter the community composition in favor of native species. Competition is a two-way street, and healthy perennial bunchgrasses can successfully compete with invaders and inhibit their spread. The goal of using livestock to control weeds is to manipulate patterns of defoliation to place a target plant at a competitive disadvantage relative to other plants in the community. There are two approaches to placing an invasive plant at a competitive disadvantage in the community: 1) use grazing manage- 
ment that harms the target weed by grazing at the time and frequency when the weed is most vulnerable, and 2) modify the grazing behavior of animals to cause them to concentrate their grazing efforts on the target weed (2). These two approaches form the framework of prescription grazing.

\section{How Livestock Can}

\section{Contribute to Weed Invasion}

Livestock grazing, like any land use, can be misapplied and cause harm instead of repair. Poor grazing management practices have been blamed for the introduction and spread of invasive plants by the degradation and reduced competitive ability of the native plant communities. Decades of overgrazing in the North American Intermountain West during the open range era paved the way for opportunistic winter annual grasses, such as cheatgrass and medusa head.

These grasses are fierce competitors that have high seedling vigor and are able to germinate, establish, and complete their life cycle before the summer dry period. The exploitation of resources by the annual grasses when combined with the overgrazing, resulted in a decline in perennial grass populations. A shift in grazing management to better utilize the annual grasses then left the community open to the next wave of invaders, forbs like yellow starthistle and rush skeletonweed.

Livestock can disperse seeds by serving as transportation vectors for seeds that adhere to their coats (fur, wool, or hair). Several weed species including houndstongue and cheatgrass practice this form of dispersion. Livestock can also spread seeds by consuming and passing viable seeds through their digestive tract. While the total number of viable seeds that survive the digestive tract is greatly reduced, those seeds that do survive are deposited in a protective pile of concentrated nutrients that can increase the chance of germination.

For example, up to $22 \%$ of spotted knapweed seeds can remain viable after passing through the digestive tracts of sheep and mule deer. Another study found that $40 \%$ of leafy spurge seeds ingested by sheep and $60 \%$ of those ingested by goats were viable on the initial day of passage. All seeds were passed within 9 days of consumption and viability of all seeds was $0 \%$ by the 5 th day after ingestion.
The longer the rate of passage through the digestive system the fewer viable seeds were recovered (4).

Though livestock grazing can increase the rate of weed invasion, the absence of grazing does not protect land from weeds. Research in western Montana found that diffuse knapweed rapidly invaded a bluebunch wheatgrass community in the absence of grazing (5). Similarly, research conducted on spotted knapweed determined that defoliation of grasses is not required for this weed to become established and that moderate defoliation did not accelerate the invasion process (6). Both spotted knapweed and leafy spurge have been documented in Glacier National Park and leafy spurge has invaded the remote Danaher Creek area of the Bob Marshall Wilderness, where there is no livestock grazing. Similarly, Anaho Island in Pyramid Lake, Nevada has not experienced livestock grazing for over 100 years and is dominated by cheatgrass and red brome. These annual grasses are sufficiently dominant on the island that the chances of natural succession progressing to pristine vegetation appear minimal.

\section{Steps in Developing a Grazing Prescription}

Just as a medical doctor requires extensive training to determine the illness or prescribe the right treatment, formulating an effective grazing prescription requires a solid understanding of plant ecology, animal behavior, and plant-animal interactions. A grazing prescription should include specific information on the season and intensity of defoliation, the species, breed, sex, and age class of animal to use, and the stocking rate that will result in the most harm to the target plant and still maintain healthy rangeland ecosystems.

A successful grazing prescription should: 1) cause significant damage to the target plant; 2) limit irreparable damage to the surrounding vegetation; 3 ) be consistent with livestock production goals; and, 4) be integrated with other control methods as part of an overall weed management strategy.

\section{Selecting the Right Species}

The species of livestock best suited for weed control depends on both the plant species of concern and the production setting. Cattle have large rumens 
that are well adapted to ferment fibrous material and are classified as grass and roughage eaters. They are therefore generally superior to goats or sheep to manage fibrous herbaceous vegetation such as dormant grasses. Goats have narrow and strong mouths well designed for stripping individual leaves from woody stems and for chewing branches. They are classified as browsers and are used extensively in the southwestern United States for management of invasive woody plants on rangelands such as juniper and mesquite $(10,11)$. Goats also have a large liver mass relative to cattle or sheep and may therefore more efficiently process plants that contain secondary compounds such as tannins or terpenes. This could explain why goats are generally more effective than sheep or cattle for the control of leafy spurge, which contains a host of allelochemicals (2).

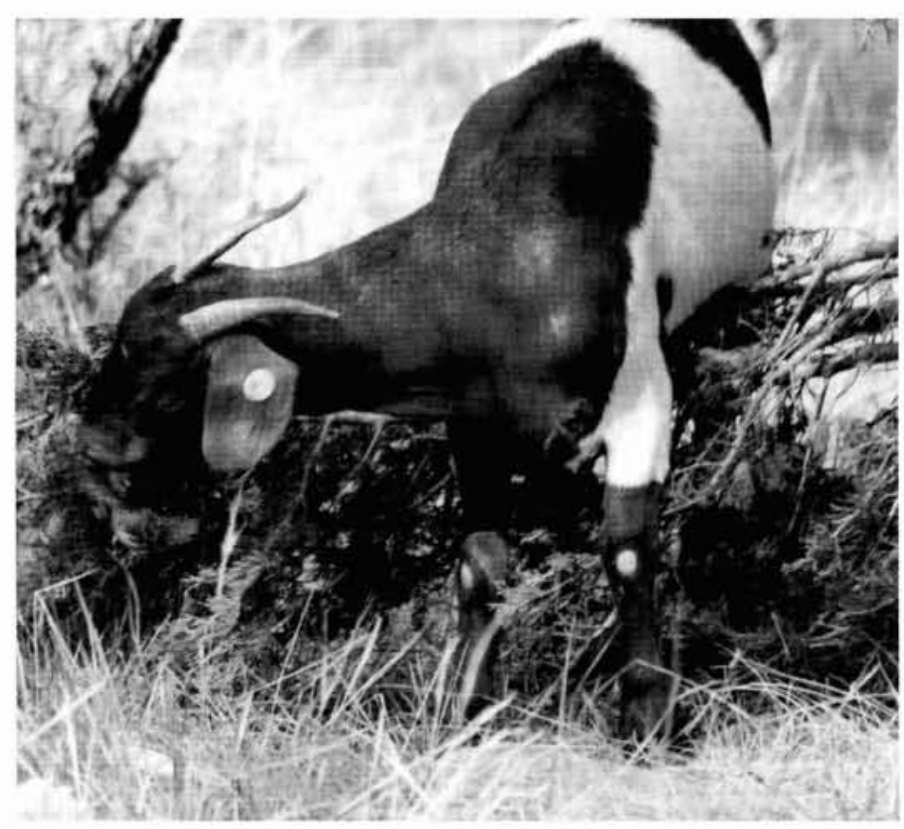

Figure 1. A goat aggressively browses redberry juniper at the Texas Agricultural Experiment Station in Sonora, Texas.

Sheep are generally considered an excellent species to accomplish control of herbaceous weeds. Sheep possess a narrow muzzle and a relatively large rumen per unit body mass. These characteristics allow them to selectively graze and yet tolerate substantial fiber content, and results in diets generally dominated by forbs. Most of the troublesome weeds that threaten rangelands are forbs. Sheep are also small, sure-footed, and well suited for travel in rough topography which may not be easily accessible for chemical weed control. Furthermore, sheep are gregarious creatures that are generally managed by human herders. This creates opportunities for careful and strategic application of grazing in specific weed dominated areas. Sheep have been used successfully for the control of several rangeland weeds including leafy spurge, tall larkspur, tansy ragwort, and others.

Selecting the right species is not the final step in matching the tool to the job. Diet composition varies among breeds and even between individual animals. What an animal consumes depends on their nutrient requirements and their past experience with a food. While animals can be encouraged to select specific plants for food, they will never habitually consume those plants if they do not receive a nutritional benefit from them. However, digestive capabilities and nutrient requirements vary throughout an animal's life potentially resulting in different nutritional benefits at different times. Therefore age, body condition, sex, and physiological state have a profound effect on diet selection and grazing preferences of the animal.

\section{Season and Intensity of Grazing}

Prescription grazing for weed control requires grazing when the weed is most palatable to livestock and most susceptible to defoliation. For instance, cheatgrass is highly palatable and is effectively reduced by heavy spring grazing. Furthermore, grazing programs should be implemented when the associated or desired plant community expresses relatively high tolerance to grazing.

The season and intensity of defoliation strongly affect the ability of plants to regrow following grazing. Most plants are tolerant of herbivory early in the growing season when adequate nutrients and soil moisture are available for regrowth. However, as the season progresses nutrient availability is reduced and plants are investing more resources into seed production. Consequently, grazing during this time can be very detrimental to plants. Furthermore, grazing weeds during seed set may not be advisable because of the risk of livestock spreading weed seeds. Seed dispersal of weeds by animals can be minimized by avoiding livestock grazing in weed-infested areas during flowering and seeding stages. Animals can also be held in pens for 
a short time period (i.e., 48 hours) to allow passage of all seeds through the digestive system before moving them to uninfested areas.

Perhaps the main factor determining stocking rate is the density of the weed infestation and the palatability of the plant. Sparse infestations of relatively nutritious, palatable plants like spotted knapweed may be best controlled with light stocking rates of sheep that can take advantage of the animal's preference for the plant. More dense infestations or less palatable weeds may require a heavy stocking rate to force a more even utilization of forage. In extremely dense infestations, animals are often "mobstocked" to facilitate complete removal of all forage. This can be accomplished by herding or fencing animals onto those areas until the desired result is achieved.

\section{Integrating Livestock Grazing Into Weed Control Programs}

Finally, it is necessary to find ways to incorporate prescription grazing into ecologically-based integrated weed management systems, with careful attention to positively directing community change and not just removing a weedy species. Incorporating grazing management into weed management plans has been recognized as one of the key components in successfully addressing weed problems. Research on leafy spurge indicates that grazing could increase the efficacy of herbicides and insect biocontrol (7). Sheep grazing may also be used to reduce recruitment of weeds after herbicide treatment. These studies suggest that grazing has the potential to increase the effectiveness of integrated pest management (IPM) systems while reducing the use of herbicides. Using grazing animals to control invasive or noxious plants is a readily available approach because it is already the dominant use of western rangelands. However, making grazing an active part of a weed control program will require greater dedication and commitment to grazing management techniques. Grazing guidelines must be developed for this technology to be utilized with maximum effectiveness.

\section{Associated Costs}

Prescription grazing holds great opportunity for incorporation into a successful weed control program; however, controlled grazing is not without cost. Animals must be purchased, maintained in proper health, and closely monitored to minimize harm to desirable forage. This may require keeping an experienced herder with the animals at all times and often necessitates penning the animals at night.

Other expenses may include stock dogs, portable fencing, and remodeling of livestock handling facilities. If the vegetation management is to occur in close proximity to towns and cities, then extra care must be taken to protect livestock from domestic dogs and ensure that they remain either fenced or directly under the herder's control. When the vegetation to be controlled contains secondary compounds or has very poor nutritional quality it may be necessary to supplement the animals.

Finally, the animal production consequences of employing grazing to accomplish weed control must be understood. Despite the potential biological efficacy of using livestock to control weeds, this practice will not be widely employed until it is shown to be compatible with production goals. For some weeds, such as leafy spurge, sheep used for weed control may outperform their counterparts on non-infested rangelands (8). However, employing animals to control weeds of low nutritional value, such as mature fibrous weeds, will undoubtedly result in some production losses.

Some argue that sheep grazing will never be an

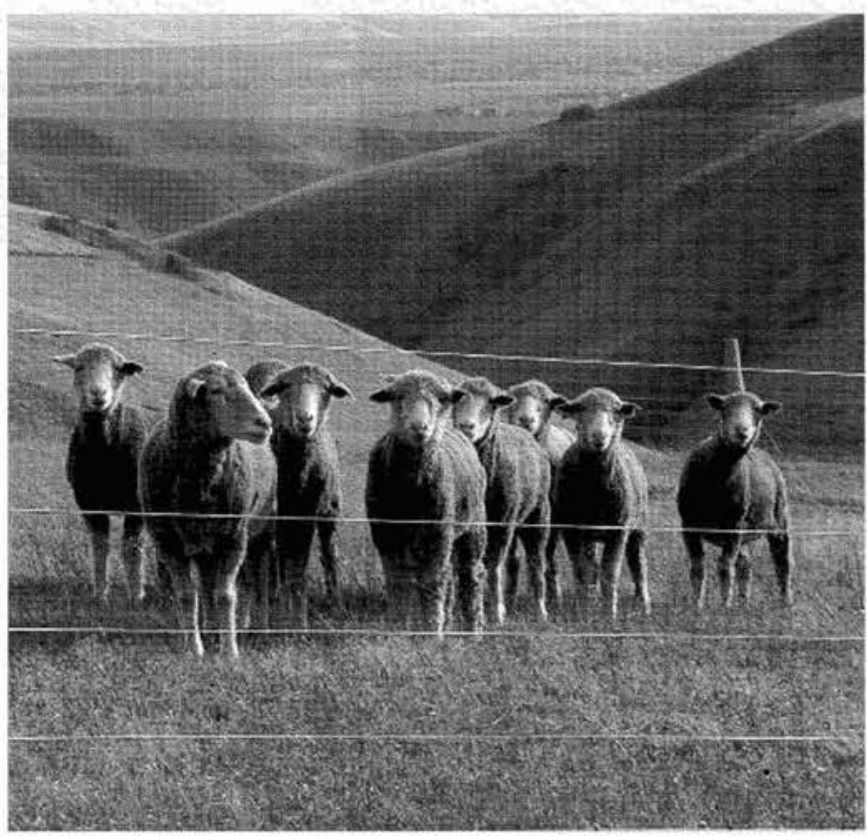

Figure 2. Sheep involved in a yellow starthistle grazing study in Northern Idaho. 
effective weed management tool because sheep availability is limited. However, sheep enterprises based on weed control are becoming more common throughout the rangelands of western North America. These enterprises are taking weed control with livestock beyond the experimental phase and are actually making their living solely by fulfilling vegetation management contracts (9). Established sheep enterprises may also consider including prescription grazing for weed control as a part of their grazing plan if it is proven to not be substantially detrimental to sheep production. Detailed information is needed on the impacts of weed consumption on sheep production before it will become widespread.

If managed correctly, prescription grazing could prove to be a winning situation for all involved. Not only does it provide a service to land owners and managers that may not be easily achieved in other ways, but it could also provide a new avenue of income to livestock producers. It is essential that we continue to gather and share information so we can constantly sharpen this "old" tool into a "new" range management option.

Authors are with the Department of Rangeland Ecology at the University of Idaho.

\section{References}

1. Olson, B.E. and J.R. Lacey. 1994. Sheep: A method for controlling rangeland weeds. Sheep \& Goat Res. J. 10:105-112.

2. Walker, J.W., S.L. Kronberg, S.L. Al-Rawaily, and N.E. West. 1994. Managing noxious weeds with livestock: Studies on leafy spurge. Sheep Research Progress Rep. No. 3, USDA-ARS 1994-4 pgs 125-135.

3. Sheley, R.L., J.S. Jacobs, and M.F. Carpinelli. 1998. Distribution, biology and management of diffuse knapweed (Centaurea diffusa) and spotted knapweed (Centaurea maculosa). Weed Technol. 12:353-362.

4. Lacey, J. R., R. Wallander, and K. Olson-Rutz. 1992. Recovery, germinability, and viability of leafy spurge (Euphorbia esula) seeds ingested by sheep and goats. Weed Technology. 6:599-602.

5. Lacey, J.R., P. Husby, and G. Handl. 1990. Observations on spotted and diffuse knapweed invasion in ungrazed bunchgrass communities in western Montana. Rangelands. 12:30-32.

6. Sheley, R.L., and J.S. Jacobs. 1997. Response of spotted knapweed and grass to picloram and fertilizer combinations. J. Range Manage. 50:263-267.

7. Lym, R.G., K.K. Sedivec, and D.R. Kirby. 1997. Leafy spurge control with angora goats and herbicides. J. Range Manage. 50:123-128.

8. Fay, P.K. 1991. Controlling leafy spurge with grazing animals. In: L.F. James, J.O. Evans, M.H. Raphs, and R.D. Childs.(ed.) Noxious Range Weeds. Westview Press, Boulder, Col.

9. Daines, R. 2002. Foraging for money. Sheep Industry News. 6:1-2.

10. Brock, J.H., 1988. Livestock: biological control in brush/weed management programs. Rangelands 10: 32-34.

11. Hanselka, C.W. and J.C. Paschal. 1992. Brush utilization on the Rio Grande Plains. Rangelands. 14:169-171.

\section{Additional Readings}

DiTomaso, J.M. 2000. Invasive weeds in rangelands: Species, impacts and management. Weed Sci. 48:255-265.

Mosley, J.C. 1996. Prescribed sheep grazing to suppress cheatgrass: A review. Sheep \& Goat Res. J. 12:74-80.

Popay, I. and R. Field. 1996. Grazing animals as weed control agents. Weed Technology. 10:217-231. 